INVESTIGACIÓN/RESEARCH

\title{
ANTECEDENTES DE RELACIONES PÚBLICAS EN LOS MANUALES DE PUBLICIDAD. ALGUNOS PRECEDENTES DE ACTIVIDAD EN ESPAÑA DESDE MEDIADOS DEL SIGLO XIX
}

Jesús Reina Estévez1: Universidad de Málaga (UMA). España.

jeres@uma.es

Ma Inmaculada González España²: Universidad de Málaga (UMA). España.

inmage@uma.es

\section{RESUMEN}

El presente estudio localiza antecedentes de relaciones públicas en los manuales de publicidad que han estudiado la situación española. A través de la revisión bibliográfica exhaustiva de las obras, se ha perseguido el objetivo de encontrar actividades precedentes de la actividad de las relaciones públicas, anteriores al comienzo oficial de la disciplina en nuestro país en la década de los 60, que fueron llevadas a cabo principalmente a mediados y finales del siglo XIX y principios del XX. La labor de rastreo conlleva el reclamar la autoría sobre algunos antecedentes de comunicación de naturaleza ambigua, que tradicionalmente se han desarrollado en el terreno de la publicidad, la propaganda y el periodismo, y reubicarlos en el ámbito de las relaciones públicas.

\footnotetext{
${ }^{1}$ Doctorando en Comunicación en la Universidad de Málaga. Interesado en los orígenes de las Ciencias de la Comunicación en España.

2 Doctoranda en Comunicación Organizacional en la Universidad de Málaga. Investigadora de los orígenes de las Relaciones Públicas en España.
} 
Historia de las Relaciones Publicas en España - Manuales de Publicidad - Antecedentes de Relaciones Publicas - Campañas de Prestigio - Agencia Danis - Agencia Ruescas Publicidad Pioneros de la Comunicación

\title{
PALABRAS CLAVE:
}

Historia de las Relaciones Publicas en España - Manuales de Publicidad - Antecedentes de Relaciones Publicas - Campañas de Prestigio - Agencia Danis - Agencia Ruescas Publicidad Pioneros de la Comunicación.

\section{PRECEDENTS OF PUBLIC RELATIONS IN ADVERTISING'S SPANISH MANUALS. SOME EXAMPLES OF PUBLIC RELATIONS IN SPAIN FROM THE NINETEENTH CENTURY.}

\begin{abstract}
The present study locates precedents of public relations in the advertising manuals that have studied Spanish situation. Through an extensive bibliographic revision of the plays, it has been possible to find isolated activities of early relation publicities, prior at the official beginning of the discipline in our country in the 60s, mainly at the end of 19th century and the start of the 20th. The tracking work requires claiming autorship for the discipline of public relations about some background of ambiguous nature, which traditionally have been moved into the fields of advertising, propaganda and journalism.
\end{abstract}

\section{KEY WORDS}

History of Public Relations in Spain - Advertising Manual - Public Relations Precedents Status Campaign - Danis Agency - Ruescas Publicidad Agency - Pioneers Comunication.

\section{INTRODUCCIÓN}

La historia de la implantación de las relaciones públicas en España está íntimamente ligada al desarrollo técnico de las agencias de publicidad patrias, pues serán estas organizaciones las que pongan en marcha en nuestro país las primeras campañas de relaciones públicas, con relativo éxito y calado. Tradicionalmente, se han considerado a las campañas de publicidad social de la agencia barcelonesa Danis como los primeros antecedentes de relaciones públicas conocidos, aunque no sean los únicos, condicionando también su nomenclatura al entorno publicitario. 
De este modo, los hipotéticos antecedentes de relaciones públicas que pueden haber existido, han pasado desapercibidos, al haber sido etiquetados erróneamente por los profesionales sobre el terreno o por los historiadores de la comunicación. Parte de esta labor de apropiación indebida procede del mundo profesional publicitario, que se ha valido de fórmulas de denominación ambiguas, al desconocer una terminología más pertinente.

Si consideramos que el mal ya está hecho, aunque se carezca de mala fe, solo nos resta a los historiadores de las relaciones públicas tratar de rastrear estos antecedentes, tarea no menos difícil e ingrata, por el esfuerzo de reclasificación que conlleva. En estos momentos, resulta indispensable empezar por el principio, por los agentes (académicos de la publicidad y profesionales) que han introducido la profesión en nuestro país, a través de las fuentes que nos han legado: sus obras sobre la historia de la publicidad en España.

\section{OBJETIVOS}

El objetivo principal de esta investigación es localizar algunos antecedentes de relaciones públicas que se habrían llevado a cabo en el territorio español, durante el largo periodo histórico que antecede al comienzo oficial de la disciplina en España.

\section{METODOLOGÍA}

El presente estudio se vale de la técnica exploratoria de revisión bibliográfica para encontrar antecedentes de las relaciones públicas en nuestro país en los manuales de publicidad de autores españoles. A partir de esta lectura crítica se obtienen ejemplos que fundamentan la teoría de una actividad previa de relaciones públicas anterior a su desarrollo oficial en España, a partir de los años sesenta del siglo XX.

Las obras que componen la bibliografía de estudio han sido agrupadas en tres tipos, dependiendo del carácter del libro y de su autor. De este modo, el Grupo 1 lo integran los manuales de publicidad, con especial hincapié en los monográficos centrados en la historia de la publicidad en España, ricos en datos y antecedentes de actividades en comunicación españolas: "Las Rutas de la Publicidad en Andalucía" de Antonio Checa Godoy (2005) ${ }^{1}$ y su "Historia de la Publicidad" (2007); "Historia de la Publicidad"2 de Raúl Eguizábal (1998); "Historia de la publicidad en España" (1971), y su versión más actualizada, "Historia de la publicidad y del arte comercial en España: desde tiempos remotos al final del siglo" (2000), de Francisco García Ruescas; “La publicidad en España: anunciantes, agencias, centrales y medios. 1850-1950" (2001), y “La transición de la publicidad española: anunciantes, agencias, centrales y medios. 1950-1980" (2003), sendas obras de Miguel Ángel Pérez Ruiz; y la pionera obra "Publicidad Combativa"3 de Pedro Prat Gaballí (1959). 
Historia de las Relaciones Publicas en España - Manuales de Publicidad - Antecedentes de Relaciones Publicas - Campañas de Prestigio - Agencia Danis - Agencia Ruescas Publicidad -

Pioneros de la Comunicación

En el Grupo 2 están localizadas aquellas obras biográficas y autobiográficas que abordan la historia de la publicidad en España de manera parcial, desde una perspectiva muy concreta, y que relatan, en algunos casos en primera persona, campañas pioneras de publicidad y relaciones públicas en España, a partir de los años 50: "Publicidad Atlantis 1945-1995: Historia de una empresa familiar", de Santiago de Luxán Meléndez y José Luís Quesada González, (1997); “Hora Cero. El ayer de la Publicidad y las relaciones públicas", de Joan Fontcuberta (1998); y, “Relatos al final del camino”, de Francisco García Ruescas, (1995).

El Grupo 3 recopila todos aquellos artículos, libros y manuales sobre la historia de la publicidad que no abordan el panorama español, o solo lo hacen de manera superficial, y cuyas aportaciones teóricas complementan, clarifican o desarrollan los datos del primer y segundo grupo (Anaut, 1990; Fernández, 2013; Sánchez Guzmán, 1989; Satué, 1991; Sueiro, 2007; Sociedad Nestlé, 1992).

Para aclarar conceptos de relaciones públicas, contextualizar debidamente las técnicas, herramientas y medios de comunicación españoles y las coyunturas históricas en que se desarrollan los antecedentes de actividades de relaciones públicas en España se han consultado numerosas obras de referencia, tanto de la historia de España en sus relaciones con los EEUU -principal país exportados de las relaciones públicas modernas en el mundo(Barjot, 2005; Puig, 2005), artículos, libros y tratados de relaciones públicas (Armendáriz, 2012; Noguero; Rodríguez Salcedo, 2007, Rodríguez Salcedo, 2010; Xifra, 2006; Xifra 2007), así como manuales de otras áreas de la comunicación, sobre todo de historia de la prensa y la opinión pública (Beneyto, 1961; Checa, 2011; Cruz \& Saiz, 2007; Gómez, 1989; González Martín, 1989), e historia del consumo en España (Alonso \& Conde, 2011).

\section{RESULTADOS}

\subsection{Propuestas cronológicas para la historia de las relaciones públicas en España: Estado de la Cuestión.}

Un primer gran grupo de los investigadores de la historia de las relaciones públicas en España establece el inicio de la profesión en los primeros años de la década de los 60, cuando nace la primera agencia íntegramente de relaciones públicas: la SAE de RP. La actividad de la SAE de RP vendría precedida por unos antecedentes de relaciones públicas, a partir de 1955, en la forma de campañas de publicidad social, llevadas a cabo por Joaquín Maestre, fundador de agencia de relaciones públicas, cuando trabajaba para la agencia de publicidad Danis (Almansa, 2011; Barquero, 2005; Castillo, 2003, Castillo, 2009; Noguero, 1994; Noguero, 1995; Noguero, 2004; Rodríguez Salcedo, 2010; Xifra, 2010).

En contra de esta tesis se encontraría un segundo grupo, integrado por los hermanos Arceo Vacas, que sostienen que la coyuntura política y comunicativa en la España previa a la 
Democracia, es decir, durante el Franquismo, no habría propiciado la existencia de unas verdaderas actividades de relaciones públicas, por no poder éstas desarrollarse en libertad (Arceo, 1995a; Arceo, 2004a; Arceo, 1995b; Arceo, 2004b; Arceo, 2006).

Un último, y tercer grupo, se ha conformado en los últimos años en el panorama de los estudios de las relaciones públicas en España, que sostienen que en nuestro país se ha venido desarrollando una actividad previa a su desembarco estadounidense tras la Segunda Guerra Mundial (Armendáriz 2012; Rodríguez Salcedo, 2007). Estas actividades, anteriores al acuñamiento del término "relaciones públicas" en castellano, habrían existido como antecedentes aislados, con otra denominación y sin una cobertura teórica ni técnica, nacidos fuera de las agencias de comunicación. Es decir, se estaría hablando de relaciones públicas avant la leerte (Armendáriz, 2012, 16), autóctonas, y amparadas en una tradición propia de relaciones públicas genuinas y europeas, anteriores al desembarco americano durante la segunda guerra mundial (Xifra, 2006, 452).

Dentro de esta última clasificación, podemos encontrar un interesante sub-grupo integrado por académicos y profesionales del mundo de la publicidad, que sin entrar en el estudio sistemático de la historia de las relaciones públicas, aportan, a través de sus obras, abundantes ejemplos y anécdotas, a nuestro juicio, de antecedentes de relaciones públicas en nuestro país (Checa, 2005; Checa, 2007; De Luxán \& Quesada, 1997; Eguizábal, 1998; Fontcuberta, 1998; García Ruescas, 1971; García Ruescas, 1995; García Ruescas, 2000; Prat Gaballí, 1959). Nos encontraríamos ante una abundante e inexplorada fuente de estudio que bien merecen una lectura más detenida.

\subsection{De los antecedentes más remotos a las actividades de relaciones públicas de finales del Siglo XIX.}

Los antecedentes más remotos de actividad de relaciones públicas en España son proporcionados también por los autores más pioneros de nuestro país. Juan Beneyto que, junto con Prat Gaballí, ha sido uno de los primeros teóricos en abordar la disciplina, escribe en 1961 sobre unas relaciones públicas de corte propagandístico y protocolario, que se daban en las Cortes Castellanas, mediante la entrega de regalos a los huéspedes regios. Una forma de proceder común de todos los príncipes medievales, y no exclusiva de Alfonso X, el sabio (Beneyto, 1961, 153).

Por su parte, Prat Gaballí localiza el origen de las relaciones públicas en el plano comercial, con el paso de una sociedad feudal a una de tipo pre-capitalista:

La necesidad de vender los productos, dándolos a conocer al mayor número posible de gentes, reunía a los mercaderes en las plazas tribales y otros lugares públicos, propagando estos concursos por vía de los pregoneros. Así surgían en el mundo las ferias locales, que tan dilatado papel habían 
Historia de las Relaciones Publicas en España - Manuales de Publicidad - Antecedentes de Relaciones Publicas - Campañas de Prestigio - Agencia Danis - Agencia Ruescas Publicidad -

Pioneros de la Comunicación

de desempeñar durante siglos y siglos. Y se dejaban fecundadas las relaciones humanas, en lo comercial, con lo que hoy llamaríamos publicidad colectiva o relaciones públicas (Prat Gaballí, 1959, p. 4).

A su vez, entre los primeros antecedentes de relaciones públicas en España encontramos lo que García Ruescas clasifica como gacetilla publicitaria sin señal de pago (1971: 65), y que se trataría de una noticia de carácter comercial publicada en el primer número de El Diario de Barcelona, el 1 de octubre de 1792. Hasta ese momento, había sido una práctica común en la prensa del siglo XVIII el afrontar los asuntos publicitarios mediante la concesión de espacios sin remuneración, ya que sus promotores creían que eran por ellos que el público compraba el periódico (Cruz \& Saiz, 2007, 40), asegurando, además, publicar toda información "que se recibiera, después de emplear cuarenta y ocho horas en depurar si eran verdaderas o falsas" (García Ruescas, 1971, 66).

El artículo, titulado "Noticia del establecimiento de las pastillas de substancias que de orden de su S.M. se ha hecho en la Provincia de Buenos Ayres para el uso de la Marina", es equiparado por Eguizábal, quizás erróneamente, con un anuncio redactado con forma periodística sobre unas novedosas pastillas de caldo en tierras españolas (1998: 441). Consideramos que bien podría ser un ejercicio pionero de publicity en nuestro país. Pues, conforme a las definiciones que Noguero i Grau recoge del Webster's Dictionary, estaríamos ante una

información con un contenido noticioso que se emite para obtener la atención y el apoyo público [...] Es la diseminación de información promocional por la prensa y otros mass media [...] Un acto o plan diseñado para atraer la atención del público (Noguero i Grau, 1995, p. 37).

Asimismo, la noticia, que se caracteriza por su carácter pseudo-científico, tan de moda en la época, entronca directamente con el espíritu del goodwill, o a la búsqueda del interés general (Sotelo, 1999, 87). De este modo, se observa que el cuerpo del texto se cierra con el compromiso social del propietario del establecimiento al destinar una porción de la mercancía "para el uso de los jornaleros y los pobres", y prometer que parte de las ganancias serán donadas, con fines caritativos, "deseando que sirva para el mayor beneficio de la humanidad".

Otra actuación de relaciones públicas de mediados del siglo XIX, mencionada por García Ruescas $(1971,114)$, la hallamos en la revista femenina "La Moda Elegante". En la editorial del primer número del año 1876, el editor Ricardo Sepúlveda hace hincapié en el sistema de visitas particulares que mantenía con las suscriptoras, en un sistema de comunicación directa entre el editor y su público, que García Ruescas etiqueta como de relaciones públicas. 
En ese mismo año, según recoge Raúl Eguizábal, uno de los grandes éxitos de la primera agencia de publicidad española, la pionera Roldós S.A., fue una vistosa puesta en escena para una máquina de coser, que llevó a cabo en el desfile de carnaval de 1876. Para llamar la atención de los asistentes y de la prensa del momento, la agencia barcelonesa se valió de una carroza con motivos publicitarios, en donde colocó una especie de ingenioso mortero de aire comprimido. Desde la misma se fueron lanzando al público miles de folletos de una máquina de coser "que la gente se pegaba por obtener. No solamente estuvo hablándose del hecho durante tiempo, lo más importante es que consiguió aumentar considerablemente la venta de dichas máquinas de coser" (Eguizábal, 1998, 449).

Dicho evento puede tipificarse como un acontecimiento especial de relaciones públicas que, citando a Jordi Xifra $(2007,179)$, permite "establecer una relación con los públicos directos (los asistentes y los medios de comunicación) y, a través de éste, con un público indirecto (la comunidad en sentido amplio), para consolidar, mejorar o crear la percepción pública".

A finales del siglo XIX, el panorama comunicativo en España ha evolucionado notablemente. La prensa política está dando paso a la prensa de empresa o información, y aparece un tipo de publicidad más madura, que escapa de la última página de las publicaciones. Rodríguez Salcedo (2007) destaca el artículo sobre la compañía suiza Nestlé, publicado el 22 de diciembre de 1881, en La Ilustración Española, dentro del apartado genérico "Industrias Modernas".

Esta comunicación en prensa se compone de "un dibujo que reproduce la fábrica de Vevey y un texto donde se explican las características de la harina lacteada, su elaboración y la predominancia que el producto ha conseguido en nuestro país" (Sociedad Nestlé A.E.P.A, 1992, 30). Según Rodríguez Salcedo (2007), éste sería el primer caso de publicidad redaccional en nuestro país, que se encuadra en el ámbito de las relaciones públicas por sus objetivos, alejándose de los productos para acercarse a la información sobre las compañías y empresas.

Otros ejemplos de publicidad redaccional, o publicty, los obtenemos de mano de Checa Godoy $(2005,32-34)$ que referencia, en la prensa gaditana de finales del siglo XIX, otros anuncios que, años más tarde, siguen el patrón señalado por Rodríguez Salcedo. La publicidad redaccional en el valioso Anuario Guía de Prensa Española y empresas conexas, editado en 1897 en Madrid por Francisco Santomé, exhibe sobre todo argumentos y razones, siempre con abundancia de datos, en una búsqueda de prestigio y de la complicidad del público.

La publicity de la Gran Fábrica de Naipes Finos incluye una ilustración de la fábrica, y un sencillo texto que describe parte de la historia y el nivel de producción y distribución de la empresa, que fabricaba cada mes 6.000 barajas y exportaba su famosa baraja andaluza a la República Mejicana y la Habana. El caso de la Fábrica de féretros, sarcófagos y arcanas-urnas Nuestra Señora del Pilar se vale de argumentos de corte social, quizás, y alega dar trabajo a más de cien obreros en algunos meses del año. Por último, resulta significativa la labor social que ilustra la Clínica del doctor Antonio Galván, que dice atender a pobres y acogidos en la Casa matriz de Expósitos, así como al numeroso personal obrero de la Compañía Trasatlántica. 
Historia de las Relaciones Publicas en España - Manuales de Publicidad - Antecedentes de Relaciones Publicas - Campañas de Prestigio - Agencia Danis - Agencia Ruescas Publicidad -

Pioneros de la Comunicación

\subsection{Algunas actividades de relaciones públicas en España a principios del Siglo XX.}

El panorama de la actividad comunicativa en la España anterior a la Guerra Civil supone un cambio progresivo a mejor en el panorama comunicativo, hasta detenerse abruptamente con el conflicto bélico. Los diarios de finales del siglo XIX presentaban ya algunas características propias de la prensa de masas, con una publicidad más madura (Gómez, 1989, 30). Al mercado español se van a ir incorporando unos nuevos objetos de consumo (automóviles, electrodomésticos, etc.), específicos del modelo de consumo de elite y preformista, que se inscriben en la lógica de la elegancia y distinción; productos que posteriormente van a caracterizar el modelo de consumo de masas de los años 60 (Alonso \& Conde, 1994, 67-73).

Estos cambios propician la creación de las primeras agencias técnicas en España, y facilitan la llegada de los grandes anunciantes internacionales, que reclaman un servicio con garantías. Durante las década de prosperidad de los años 20 desembarcan en España, entre otras empresas (Eguizábal, 1998: 454): la Sociedad petrolífera Shell (Madrid, 1920); Nestlé (Barcelona, 1920); General Eléctrica (Bilbao, 1929); ITT Compañía Telefónica Nacional de España (Madrid, 1923-24); Hispana Olivetti (Barcelona, 1929); Coca-Cola (Madrid, 1930), etc.

Las marcas, aliadas con estas agencias de corte técnico, ponen en marcha unas campañas de comunicación más elaboradas y efectivas (García Ruescas, 2000: 195). El caso de la malagueña Ceregumil se encuentra entre las firmas más activas e importantes de Andalucía, según Checa Godoy $(2005,58)$. A su destacada comunicación publicitaria, hay que recalcar las actividades de relaciones públicas que en 1924 lleva a cabo, mediante el uso de relojes, plumas estilográficas e incluso lámparas con el logo de la firma.

Las agencias publicitarias españolas de principios y mediados del siglo XX han sido el vehículo por el que históricamente las relaciones públicas modernas entran en nuestro país, frente a las actuaciones aisladas que se pudieran dar en el siglo anterior, por parte de particulares y organizaciones privadas. Los motivos de esta situación, frente al modelo americano, a nuestro juicio y sin pretender ser exhaustivos, los podemos hallar en las características del modelo empresarial y comunicativo: la mayoría de las empresas españolas son pequeñas, de corte familiar, y no sienten la necesidad de comunicar más allá de los anuncios publicitarios; la debilidad del entramado periodístico, que minusvalora los contenidos de tipo comercial y no recaba las informaciones procedentes de las empresas, por lo que no deja espacio para que unos profesionales se erijan como portavoces de las compañías, y el limitado campo de actuación de las agencias de publicidad, que ven en la creatividad y la comercialización de espacios su única forma de negocio.

Será en la búsqueda de la prestación de unos servicios cada vez más profesionales y elaborados, el camino por el que las agencias de publicidad españolas llegarán al terreno de las relaciones públicas, siempre a la sombra de los formatos publicitarios. A modo de ejemplo, se puede acudir a la obra de Prat Gaballí, Publicidad Combativa (1934), referenciado 
por Pérez Ruiz $(2001,146)$, que al hablar de los formatos de publicidad en prensa, enumera el anuncio disimulado, como aquella "publicidad encubierta en una información", que sería otra forma de denominar a la publicity en prensa.

\subsection{Fin de la autarquía y primeras campañas de relaciones públicas en el seno de las agencias de publicidad españolas.}

Las agencias publicitarias españolas, que tan brillantemente se habían desarrollado en las décadas previas a la Guerra Civil, y bajo una fuerte influencia europea, en el período de entreguerras vieron su actividad disminuidas o extinguidas durante la autarquía (Puig, 2005, 196). Como bien resume Pérez Ruiz,

desde el año 1937, la publicidad se viene abajo. Una sociedad que no tiene qué comer no necesita publicidad para elegir la marca o producto que va a comprar [...] la publicidad se orienta totalmente hacia la política. Es decir, se emplea con fines ideológicos, no para promocionar bienes (Pérez Ruiz, 2001, p. 189).

El sector comunicativo en España irá recuperando entonces tímidamente su lugar, pero tratando de adaptarse a las nuevas técnicas imperantes. Los últimos años de la década de los años cuarenta son cruciales porque ya presentan algunos signos de mejora, incluso en el terreno de las nuevas relaciones públicas, que siguen sin ser conocidas por esta denominación.

La serie de portadas que recopila Prat Gaballí (1959), nos permite afirmar que desde mediada la década de los 40 ya existen casos de edición en España de revistas privadas o de empresa. Un ejemplo del uso de este instrumento de relaciones públicas lo encontramos en el longevo "Boletín de Información" de la marca Firestone-Hispania, que abrió su primera fábrica en Basauri (Bilbao) ${ }^{4}$, en Octubre de 1933. El folletín empezó a editarse a partir de 1947, y se trataba de un facsímile de 24 páginas, que salía con una periodicidad mensual.

También este autor pionero da datos sobre el órgano privado de la Compañía Kodak, que se distribuye a partir de 1948, la revista Radiografía y Fotografías Clínicas. Del primero explica Prat Gaballí que había sido

creado en España, con la facilidad de ejercer una acción educativa y de estímulo comercial entre sus distribuidores", y de la revista aclara que estaba "destinada a facilitar información de carácter científico y crear buena voluntad entre médicos y odontólogos (Prat Gaballí, 1959, p. 80). 
Historia de las Relaciones Publicas en España - Manuales de Publicidad - Antecedentes de Relaciones Publicas - Campañas de Prestigio - Agencia Danis - Agencia Ruescas Publicidad -

Pioneros de la Comunicación

Durante estos años, comienza una época de crecimiento para las agencias de publicidad españolas, llegando siete de ellas a controlar alrededor del 70\% de la facturación en medios, Alas, Cid, Publicitas, La Universal, Gisbert, y también Ruescas Publicidad y Atlantis (Pérez Ruiz, $2003,45)^{5}$.

Esta última, la agencia Publicidad Atlantis, radicada en las Islas Canarias, organizó para la marca Domecq, durante la década de los 50, una serie de eventos en público y sorteos de codiciados vehículos. La organización de los eventos incluía la presentación del acto de entrega del coche premiado en las localidades de las islas, regalar muestras gratuitas de los productos, y repartir copias de los anuncios impresos, además de otras labores de relaciones públicas, como el trato directo con los públicos que se acercaban a hablar con los trabajadores de la agencia (De Luxán \& Quesada, 1997).

\subsection{Especial atención a la figura de Francisco Ruescas como pionero de las relaciones públicas en España.}

En estos años de maduración comunicativa no faltan los profesionales que se interesan por el nivel superior que presentan las agencias norteamericanas, que habían llegado a nuestro país junto con un aluvión de empresas transnacionales y sus nuevos productos de consumo: Camel, Winston, Reynol, Coca cola, Cavalier, Pan Américan, Kodak, Colgate-Palmolive, etc. (Pérez Ruiz, 2003, 19).

En 1946, Francisco García Ruescas realiza un viaje de cuatro meses de duración a EEUU, con el propósito de conocer de primera mano el sistema de publicidad norteamericano. De su estancia destaca el modelo norteamericano de agencia de cuentas, que se caracteriza por no llevar a clientes competidores entre sí y ofrecer un servicio integral y completo. En aquel entonces, la fórmula de trabajo de las agencias españolas se erigía sobre una obsoleta gestión en exclusiva del medio, (ya fuera radio, cines o prensa). De esta manera, la agencia convertía a cada anunciante en un cliente, que peleaba con el resto por una parte de la eficacia comunicativa en el medio (García Ruescas, 1995, 97).

A su vuelta a España, el publicitario decide importar el modelo americano, y lo integra en su agencia de nueva creación, Ruescas Publicidad, nacida en 1949. La empresa se constituye como una agencia de servicios plenos, $\mathrm{y}$, como recoge el historiador de la publicidad Raúl Eguizábal $(1998,487)$, inicia unos pioneros servicios de relaciones públicas.

\subsubsection{Anuario GARU y otros servicios iniciales de relaciones públicas.}


Uno de los primeros servicios que implantó la agencia Ruescas Publicidad fueron los de relaciones públicas, según afirma su fundador en sus memorias, con la difusión de noticias e informaciones sobre las actividades de sus clientes: "Editamos un boletín mensual para información de nuestros clientes y al mismo tiempo como vehículo de promoción" (García Ruescas, 1995, 102).

También a finales de 1948, se empezó a confeccionar el "Primer Anuario Artístico Publicitario GARÚ", que refleja en sus páginas las empresas de publicidad existentes, y reúne las campañas más exitosas del momento, que seguiría siendo editado en años posteriores. En 1949 se distribuye el "II Anuario Artístico Publicitario GARÚ".

\subsubsection{Inauguración del Hotel Castellana-Hilton.}

En 1953, España firma con Estados Unidos un triple acuerdo de índole económica, militar y técnica que sirve para poner fin al aislamiento internacional del régimen franquista (Barjot, 2005, 169). En el plano publicitario, considera Puig que la hegemonía americana,

estaba plenamente consolidada, lo que explica la americanización del mercado publicitario español que tuvo lugar, de las manos de filiales de agencias americanas [...] o de asociaciones entre éstas y las agencias locales más relevantes (como Clarín, Alas, Tiempo y Danis). La publicidad fue un instrumento esencial en lo que los funcionarios, consultores e inversores norteamericanos de la época llamaron educación económica de los españoles (Puig, 2005, p. 196).

En ese mismo año, julio de 1953, la agencia Ruescas Publicidad se hace cargo de la organización de un importante evento pionero en nuestro país, al llevar a cabo una de las primeras actividades de relaciones públicas de la historia de España: la inauguración oficial del Hotel Castellana-Hilton.

Según García Ruescas, la agencia contaba en aquellos momentos con un equipo de máximo rendimiento enfocado hacia las relaciones públicas: se habrían destinado hasta dos redactores, un fotógrafo y unos auxiliares para coordinarse con los clientes y establecer el contacto y las relaciones con los medios de comunicación. Desde la etapa inicial, la Imagen Corporativa del proyecto habría estado a cargo de la agencia.

Al llegar la fecha de los actos de inauguración oficial del Hotel Castellana-Hilton, 15 de Julio de 1953, cuenta García Ruescas $(1995,111)$ que la agencia había logrado despertar convenientemente una gran expectación social por el lujo y la modernidad que desprendía el hotel, así como por la lista de invitados, donde destacaba la asistencia de famosas estrellas del mundo del cine estadounidense, a modo de acertado reclamo mediático. 
Historia de las Relaciones Publicas en España - Manuales de Publicidad - Antecedentes de Relaciones Publicas - Campañas de Prestigio - Agencia Danis - Agencia Ruescas Publicidad -

Pioneros de la Comunicación

El autor menciona la amplia recepción que obtuvo la información en diarios y revistas, que informaron sobre el evento antes, durante y después de llevarse a cabo, con la presencia de corresponsales especiales ${ }^{6}$. La agencia se encargó de enviar y redactar los comunicados de prensa, atender a los periodistas, y gestionar cualquier eventualidad para facilitar la correcta publicación de noticias y fotografías (García Ruescas, 1995, 112).

\subsubsection{Exposición de cuadros "Ciudades del Canadá", patrocinada por Seagram.}

En 1954, la agencia Ruescas Publicidad gestionó una exposición de obras de arte de Canadá, patrocinada por la marca de whisky Seagram, para dar a conocer a la marca en nuestro país (García Ruescas, 1971, 273). El objetivo cultural de la exposición era mostrar una imagen cuidada y diferente del país canadiense, alejada del estereotipo de región invernal de nieves perpetuas, por lo que se hacía hincapié en sus veranos, con sus paisajes verdes floridos.

El papel de la Casa Seagram en el evento pasó a un segundo plano, y se limitó al patrocinio y al sufragio de los costes. Desde la llegada de los cincuenta baúles con los doscientos cuadros a Madrid, contaron con la cobertura de la prensa, aunque el nombre de la marca fue omitido hasta que se presentó la exposición a la prensa7.

El acto inaugural fue un acontecimiento pionero de organización de grandes eventos sociales durante la época de los cincuenta en España. Según García Ruescas (1995, 113), la agencia coordinó cada una de las distintas fases de esta campaña de relaciones públicas, que incluyó: la presentación de la exposición a los medios de comunicación en un almuerzo privado, el envío de mil invitaciones, seleccionar e instruir a las azafatas de la recepción del evento, y montar una infraestructura especializada en la oficina de la agencia, para el correcto envío y recepción de mensajes e informaciones.

La apertura de la exposición fue un éxito, y se alcanzó una asistencia al acto del $92 \%$ de las invitaciones enviadas. El acto oficial de la inauguración fue precedido por unas palabras del director de Seagram en Europa. Al día siguiente, Doña Carmen Polo de Franco visitó la exposición en persona, siendo recibida por los embajadores canadienses ${ }^{8}$.

Afirma García Ruescas que a la exposición asistieron más de 12.000 visitantes, asistencia multitudinaria que se controló diariamente:

Los días siguientes se abrieron los salones para el público; estaba previsto que durase ocho días, pero en vista de la aglomeración, hubo que ampliar a doce, igual número de días que estuvo abierta la exposición en los EEUU. Había, sin embargo, una gran diferencia: la exposición de Madrid, aparte del éxito inaugural, [...] superó en 3.000 los asistentes en Nueva York (García Ruescas, 1995, p. 114). 


\subsubsection{Otras actividades de Relaciones Públicas: La World Promotion Pictures y el Patrocinio Hípico de los cigarrillos Camel.}

Otras actividades de relaciones públicas que llevó a cabo la agencia Ruescas Publicidad en la década de los cincuenta, incluye la gestión del patrocinio de los concursos hípicos, por parte de la marca de cigarrillos Camel (García Ruescas, 1971, 273), y los servicios de relaciones públicas en 1959 para la World Promotion Pictures, una asociación que representaba a la industria cinematográfica norteamericana en el festival de cine de San Sebastián9. La labor de la agencia fue la de coordinar los contactos entre los invitados extranjeros y la dirección del evento (García Ruescas, 1995, 115).

\subsection{Situación de las relaciones públicas en otras partes de la geografía española.}

Paralela a la actividad en Madrid, se encuentran las "campañas sociales", que tampoco se valen de la nomenclatura de relaciones públicas, que la agencia Danis desarrolló en Barcelona, a mediados y finales de los años 50 (Fontcuberta, 1998, 176-186). Destaca la serie de anuncios "Ser Mejores" para la marca Cadie-Mistol, de 1955; "Grandes Amigos de la Humanidad", para Rocalia; y la "Campaña de Circulación" de Transportes Ochoa en 1958.

Joaquín Maestre, que recala en Danis en 1956 y se encarga de organizar algunas acciones de recuerdo sobre la campaña "Ser Mejores", será quien conciba el resto de "campañas de prestigio", o de relaciones públicas, que lleva en adelante la agencia Danis. Noguero i Grau, que se ha erigido como uno de los primeros investigadores de la historia de las relaciones públicas, asegura que "Ser Mejores" de Mistol es la primera campaña que se hace con el nombre de relaciones públicas en España (Almansa, 2011, 37). En retrospectiva, Joaquín Maestre aclara que la campaña no se había concebido para la venta del producto, sino como un apunte de programa social que pretendía una mejora de las relaciones humanas, y que finalmente repercutiría en un ambiente de buena voluntad para el producto y la firma (Noguero, 1995, 140).

En 1960, el pionero de las relaciones públicas Joaquín Maestre deja Danis y funda la Sociedad Anónima Española de Relaciones Públicas ( $S A E$ de $R P$ ), primera agencia que utiliza la denominación "de relaciones públicas" de manera explícita y consciente, y ofrece servicios plenos de relaciones públicas. Natalia Rodríguez Salcedo ha investigado la historia de la $S A E$ de $R P$ y señala que sus primeras actividades se centraron básicamente en la organización de eventos (Rodríguez Salcedo, 2010, 61-89): como el I Certamen Español de la Moda Masculina, organizado para el Consejo Español de Sastres en 1960, las celebraciones de los cincuenta años de los Almacenes Jorba en 1961, y la puesta en marcha del salón específico gastronómico Hogarotel en 1962 y el Festival de la Infancia en 1963, entre otros cuantos. 
Historia de las Relaciones Publicas en España - Manuales de Publicidad - Antecedentes de Relaciones Publicas - Campañas de Prestigio - Agencia Danis - Agencia Ruescas Publicidad -

Pioneros de la Comunicación

Con estos primeros pasos, que ya hacen gala de la nomenclatura oficial, comienza con timidez la historia de las relaciones públicas en España, y todo lo anterior habrán de ser los antecedentes.

\section{DISCUSIÓN}

El carácter genérico de las obras estudiadas, aún cuando se centren sólo en el panorama español, pasa por alto las descripciones de hechos concretos, incluso de campañas publicitarias, pues la información se trata desde una perspectiva globalizadora, homogénea y superficial. Sólo en los manuales que estudian periodos muy concretos, es posible encontrar una abundancia de datos, experiencias y anécdotas, algunas de las cuales resultan estar encuadradas en el ámbito de las relaciones públicas. Es de esperar que en el futuro las investigaciones adquieran un carácter más monográfico y pormenorizado, tanto en el ámbito de la historia de la publicidad como en el de las relaciones públicas.

Así mismo, hallamos que la actitud de los investigadores de la publicidad peca de acaparadora. Ante la duda a la hora de clasificar una actividad comunicativa, los historiadores de la publicidad optan por incluirla en el orbe de actuación de la publicidad. Este proceso de clasificación no está exento de dificultades, ni es del todo excluyente, y debería quedar sometido al debate y discusión, siempre enriquecedores. Por lo tanto, es obligación del investigador de las relaciones públicas el reclamar lo que considera suyo, ya sea rescatándolo del olvido, o declarando su autoría.

Respecto al futuro de los estudio sobre la historia de las relaciones públicas en España cada vez parece más acuciante que los investigadores se reúnan y trabajen para poner en común una cronología detallada del desarrollo de la disciplina. Los intentos particulares hasta ahora (Arceo, 2006; Rodríguez Salcedo, 2010) carecen del deseable consenso por parte de la comunidad científica, por ello es necesario seguir recabando datos, ahondar en el estado de la cuestión, y establecer nuevas líneas de investigación más minuciosas y ambiciosas.

También la localización de antecedentes de las relaciones públicas forma parte de estas deseables, por nosotros, líneas de investigación futuras. La plasticidad de herramientas, técnicas y formatos de sus actividades posibilitan que la disciplina tome parte en múltiples áreas, y escenarios y no sólo en el terreno comercial y publicitario, como el entramado turístico, la prensa comercial o formas de propaganda cultural. Queda en nuestras manos seguir revisando estas bibliografías y otras obras de referencias. 


\section{REFERENCIAS.}

Almansa Martínez, A. (2011). Del gabinete de prensa al gabinete de comunicación: la dirección de comunicación en la actualidad. Zamora: Comunicación Social y Publicaciones

Alonso, L. E. \& Conde, F. (1994): Historia del Consumo en España: Aproximación a sus Orígenes. Madrid: Debate.

Anaut, N. (1990): Breve historia de la Publicidad. Buenos Aires: Editorial Claridad.

Arceo Vacas, A. (1999a). Estrategias de Relaciones Públicas: Metodologías. Madrid: ICIE, Universidad Complutense de Madrid.

Arceo Vacas, A. (2004a). La teoría de las Relaciones Públicas. En Arceo Vacas, J.L. (dir.), Las Relaciones Públicas en España, (pp. 337-359). Madrid: McGraw-Hill.

Arceo Vacas, J. L. (1999b). Tratado de Publicidad y Relaciones Públicas. Madrid: ICIE, Universidad Complutense de Madrid.

Arceo Vacas, J. L. (2004b). Las relaciones públicas en España. Barcelona: McGraw-Hill.

Arceo Vacas, J. L. (2006). La investigación de relaciones públicas en España. Revista Análisi. Quaderns de Comunicació i Cultura, 34, pp. 111-124.

Armendáriz, E. (2012). Relaciones Públicas pioneras en España. Algunos precedentes en la primera mitad del siglo XX y pasos preliminares de la nueva profesión. Revista Análisi. Quaderns de Comunicació i Cultura, 45, pp. 15-31. 
Historia de las Relaciones Publicas en España - Manuales de Publicidad - Antecedentes de

Relaciones Publicas - Campañas de Prestigio - Agencia Danis - Agencia Ruescas Publicidad Pioneros de la Comunicación

Barjot, D. (2005). La aplicación del Modelo Norteamericano en Europa durante el siglo XX. En Delgado Gómez-Escalonilla \& Elizalde, D. (edit.), España y Estados Unidos en el Siglo XX, pp. 157-180. Madrid: Consejo Superior de Investigaciones Científicas.

Barquero Cabrero, J.D. (2005). Comunicación estratégica: Relaciones Pública, Publicidad y Marketing. Madrid: McGraw-Hill.

Beneyto, J. (1961). Teoría y Técnica de la Opinión Pública. Madrid: Editorial Tecnos.

Castillo Esparcia, A. (2003). Comunicación, Relaciones Públicas y Sociedad: Perspectivas Históricas. En Company et al (coord.), Aportacions de la comunicació a la comprensió i construcció de la història del segle XX: la comunicació audiovisual en la historia (p. 201-209). Volume II. Palma: Universitat de les Iles Balears.

Castillo Esparcia, A. (2009). Relaciones Públicas: teoría e historia. Barcelona: Editorial UOC.

Checa Godoy, A. (2005). Las rutas de la publicidad en Andalucía. Sevilla: Fundación José Manuel Lara.

Checa Godoy, A. (2007). Historia de la publicidad. La Coruña: Netbiblo.

Checa Godoy, A. (2011). Historia de la Prensa Andaluza. Sevilla: Alfar.

Cruz, Ma .C. \& Saiz, Ma.D. (2007). Cuatro siglos de periodismo en España: de los avisos a los periódicos digitales. Madrid: Alianza.

De Luxán, S. \& Quesada, J.L. (1997). Publicidad Atlantis 1945-1995: Historia de una empresa familiar. Las Palmas de Gran Canaria: Servicios de Publicaciones de la Universidad de Las Palmas de Gran Canaria.

Eguizábal Maza, R. (1998). Historia de la publicidad. Madrid: Eresma-Celeste. 
Fontcuberta, J. (1998). Hora Cero: El ayer de la publicidad y las relaciones públicas. Barcelona: Thassalia.

Fernández Poyatos, $M^{\mathrm{a}}$ D. (2013). Propuestas Cronológicas para la Historia de la publicidad. Revista Historia y Comunicación Social, 18, pp. 267-277.

García Ruescas, F. (1971). Historia de la publicidad en España. Madrid: Editora Nacional.

García Ruescas, F. (1995). Relatos al Final del Camino. Madrid: Diamer.

García Ruescas, F. (2000). Historia de la publicidad y del arte comercial en España: desde tiempos remotos al final del siglo. Madrid: Editorial Arus.

Gómez Mompart, J.L. (1989). ¿Existió en Espala prensa de masas? La prensa en torno a 1900. En Timoteo Álvarez, J. (coord.), Historia de los medios de comunicación en España: periodismo, imagen y publicidad (1900-1990), (pp. 27-40). Barcelona: Editorial Ariel.

González Martín, J.A. (1989). La Publicidad Española: Orígenes y Consolidación. En Timoteo Álvarez, J. Historia de los medios de comunicación en España: periodismo, imagen y publicidad (1900-1990), (pp. 141-150). Barcelona: Editorial Ariel.

Noguero i Grau, A. (1994). La historia de las Relaciones Públicas en España: 1954-1990. Revista Universitaria de Publicidad y Relaciones Públicas, 1(2), pp. 67-90.

Noguero i Grau, A. (1995). La función social de las relaciones públicas: Historia, teoría y marco legal. Barcelona: EUB.

Noguero i Grau, A. (2004). Principales acontecimientos en la evolución de las Relaciones Públicas en España. En Arceo Vacas, J.L. (dir.), Las Relaciones Públicas en España (pp. 337-359). Madrid: McGraw-Hill. 
Historia de las Relaciones Publicas en España - Manuales de Publicidad - Antecedentes de

Relaciones Publicas - Campañas de Prestigio - Agencia Danis - Agencia Ruescas Publicidad Pioneros de la Comunicación

Pérez Ruiz, M.A. (2001). La publicidad en España: anunciantes, agencias, centrales y medios. 18501950. Madrid: Editorial Fragua.

Pérez Ruiz, M.A. (2003). La transición de la publicidad española: anunciantes, agencias, centrales y medios. 1950-1980. Madrid: Editorial Fragua.

Prat Gaballí, P. (1959). Publicidad Combativa. Barcelona: Editorial Labor, $2^{\text {a }}$ Edición.

Puig, N. (2005). La ayuda económica de Estados Unidos y la Americanización de los Empresarios Españoles. En Delgado Gómez-Escalonilla, L., \& Elizalde, D. (edit.), España y Estados Unidos en el Siglo XX, (pp. 181-205). Madrid: Consejo Superior de Investigaciones Científicas.

Rodríguez Salcedo, N. (2007). La historia como tendencia actual de las relaciones públicas. Ponencia presentada en el Congreso Tendencias actuales de las Relaciones Públicas, de la Asociación de Investigadores en Relaciones Públicas (AIRP).

Rodríguez Salcedo, N. (2010). Historia de la publicidad y de las relaciones públicas en España. Su dimensión social y cultural. Siglos XIX y XX. En Montero, M., Rodríguez Salcedo, N. \& Verdera, F. La edad de oro de la comunicación comercial. Historia de la publicidad y de las relaciones públicas en España (pp. 61-105). Volumen 2. Sevilla, Zamora: Comunicación Social Ediciones y Publicaciones.

Sánchez Guzmán, J.R. (1989). Breve historia de la publicidad. Madrid: Editorial Pirámide.

Satué, E. (1991). El libro de los Anuncios. II. Años de Aprendizaje (1931-1939). Barcelona: Altafulla.

Satué, E. (1991). El libro de los Anuncios. III. Volver a empezar (1940-1962). Barcelona: Altafulla. 
Selltiz, C., Lawrence, S. \& Cook, S. (1980). Métodos de investigación en las relaciones sociales. Madrid: Ediciones Rialp.

Sociedad Nestlé A.E.P.A (1992). Una Historia de la Publicidad Española: Reflejos de más de un siglo de Nestlé. Barcelona: Montserrat Mateu.

Sotelo Enriquez, E. (2008). Introducción a la comunicación institucional. Barcelona: Ariel.

Sueiro, S. (2007). Posguerra: Publicidad y Propaganda [1939-1945]. Madrid: Círculo de Bellas Artes.

Xifra, J. (2006). Pioneros e ignorados: la escuela de París y la Doctrina Europea de Relaciones Públicas. En Ámbitos, Revista Andaluza de Comunicación, 15, 449-460.

Xifra, J. (2007). Técnicas de las Relaciones Públicas. Barcelona: Editorial UOC.

Xifra, J. (2010). Relaciones Públicas, empresa y sociedad. Barcelona: Editorial UOC.

\section{NOTAS.}

${ }^{1}$ Este manual aporta numerosos ejemplos de antecedentes de relaciones públicas en Andalucía desde finales del siglo XIX, señalados como tales por el propio autor, reconociendo su existencia temprana.

2 En concreto el apéndice, "Esquema histórico de la publicidad en España", pp. 439-511, dedicado íntegramente en la historia de la publicidad en España.

3 Especialmente el capítulo 2: "Evolución de la publicidad en nuestro siglo", pp. 14-42, que contiene un epígrafe dedicado a la situación española: "La publicidad en España desde 1911", pp. 35-42.

4 Fotografías de la fábrica a toda página, publicada en Boletín de Información FirestoneHispania, Año 1, nº 4, 1947.

5 Anuario de la Prensa Española 1955-56. 
Historia de las Relaciones Publicas en España - Manuales de Publicidad - Antecedentes de

Relaciones Publicas - Campañas de Prestigio - Agencia Danis - Agencia Ruescas Publicidad Pioneros de la Comunicación

6 "Americanos en Madrid", en La Vanguardia Española, 14 de julio de 1953, pp. 9; "Los Americanos descubren España", en La Vanguardia Española, 15 de julio de 1953, pp. 1; Publicidad de la Agencia Ruescas donde se anuncian las firmas que han participado en la apertura del Hotel Castellana-Hilton, en ABC, 15 de julio de 1953, pp. 6; "Fin de los actos inaugurales del Castellana-Hilton", en La Vanguardia Española, 16 de julio de 1953, pp. 1.

7 "Llegan a Madrid los cuadros de la Exposición Canadiense", en La Vanguardia Española, 8 de Marzo de 1954, pp. 7.

8 "Doña Carmen Polo de Franco visitó anoche la exposición de pintura canadiense", en ABC, 13 de Marzo de 1954, pp. 27.

${ }_{9}$ En la revista Blanco y Negro, 25 de Julio de 1959, pp. 83; la noticia de la película ganadora de la Concha de Oro, que Francisco García Ruescas (1995: 115) utiliza como referencia al confundir las fechas.

\section{AUTORES:}

Jesús Reina Estévez: Doctorando en Comunicación en la Universidad de Málaga. Interesado en los orígenes de las Ciencias de la Comunicación en España. jeres@uma.es

Ma Inmaculada González España: Doctoranda en Comunicación Organizacional en la Universidad de Málaga. Investigadora de los orígenes de las Relaciones Públicas en España. inmage@uma.es 